\title{
Communicating radiological science in the journal
}

\author{
Nagara Tamaki
}

Published online: 5 March 2014

(C) Japan Radiological Society 2014

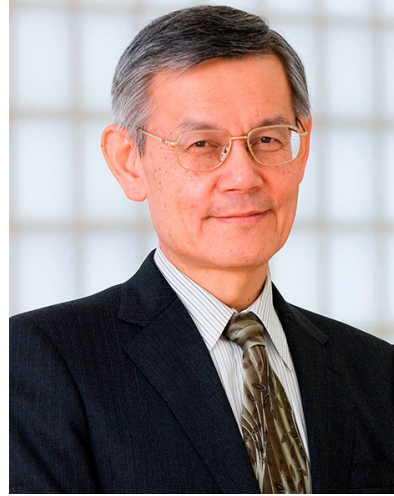

Publishing makes scientific communication widely available. Over the decades, enormous scientific papers have been published in thousands of journals. Interested readers have been faced with overwhelming difficulty in selecting the most interesting articles among many journals. In that sense, charming titles with concise abstracts should play an important role attracting many readers. When readers find informative papers, they have a wonderful chance to immerse themselves in the concept, results, and discussion in the paper. The readers may agree with the authors' opinion, or they may oppose the conclusions of the paper. By any means, the readers will enjoy such scientific communications with authors through the journals.

In the field of radiological science, rapid development of technology for imaging, intervention, and radiation oncology permits enormous advances for diagnosis and patient care. Some papers may introduce and validate the

N. Tamaki $(\bowtie)$

Department of Nuclear Medicine, Hokkaido University Graduate School of Medicine, North 15, West 7, Kita-ku,

Sapporo 060-8638, Japan innovative technologies. Some other papers may confirm image interpretation on the basis of molecular and pathological findings. Others may provide a better clinical and/or prognostic outcome for each patient through suitable imaging, intervention, or radiation therapy. Such advances permit higher standards of basic science, more suitable diagnosis and treatment, and personalized medicine. In various radiology journals, many radiologists and/or scientists will communicate with authors in various fields among radiological sciences. There are so many articles submitted, reviewed, and finally accepted for publications in this field. An increase in the impact factor of radiologyrelated journals these past years may explain how much interest there is in this field.

Our Journal, "Japanese Journal of Radiology" has enjoyed wonderful growth over the past five years. The number of article submissions is increasing by almost a hundred each year. Approximately $60 \%$ of the total submitted papers come from outside of Japan. In this sense, this has really become an international journal. There are so many attractive papers submitted, but we have to limit the publication due to the limited space, despite monthly publication since 2012. The acceptance rate has gone down far below $30 \%$ last year, which seems to be similar to many of top-ranking radiology journals. The interval from acceptance to the publication is quite short. The interval from submission to the first response from editor remains short. The interval from receipt to online publication is approximately 23 days. Many good journals do not receive "case reports," in order to increase their impact factor. We have had long discussions on how to handle case reports for our journal. We consider that some of the case reports are quite innovative and worthy of publication, despite many others being much less attractive and unsuitable to be cited. Therefore, we have decided to select only "very 
important " case reports for publication. Anyway, we would like to have "good papers" rather than "many papers" for submission for our journal.

The most excellent paper has been selected by editorial members, to be recognized during each Annual Meeting of Japanese Radiological Society. In addition, the most cited paper will be announced and recognized from this year onward. Such an award system will encourage many scientists to submit high-quality papers for our journal.
I would like to close by expressing my sincere gratitude to those people who dedicate their time and professional expertise to the success and growth of the journal. I trust that this journal will continue to make valuable progress in these years.

Nagara Tamaki Editor-in-Chief, Japanese Journal of Radiology 